\title{
MRS reports election results for 2019
}

\author{
www.mrs.org/governance
}

$\mathrm{M}_{\mathrm{s}}$

embers of the Materials Research

Society (MRS) have elected a vice president (who will serve as president in 2020) and seven directors to join the 2019 MRS Board of Directors. The Board is composed of four elected officers and up to 18 board members, 15 of whom are elected by the membership. A fifth officer (treasurer) is appointed yearly.

The MRS Board of Directors is the highest governing body of MRS, responsible for establishing policy, monitoring progress of the Society toward its long-term goals, and setting the strategic directions for the major activities of the Society, including its meetings, publications, interactions with government agencies, and cooperative efforts with other professional societies throughout the world.

The officers of the Society are the president (who serves as chair of the Board), the vice president (who is also the president-elect), the secretary, the treasurer (a position appointed by the Board of Directors), and the immediate past president. All members of the Board, except the president, serve on one of seven Board Committees: Audit, External Relations, Finance, Governance, Nominating, Operational and Strategic Oversight, and Planning. Terms of office expire at the end of the year indicated in parentheses. The asterisk (*) designates those who are newly elected. The annual election ended August 31, 2018.

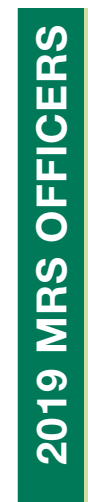

President

Michael R. Fitzsimmons

Oak Ridge National Laboratory

and The University of Tennessee

Immediate Past President

Sean J. Hearne

Sandia National Laboratories

Vice President (President-Elect)

* Matt Copel

IBM T.J. Watson Research Center

\section{Secretary}

Eric A. Stach

University of Pennsylvania

Treasurer

David J. Parrillo

The Dow Chemical Company

Executive Director

Todd M. Osman

Materials Research Society
* Monica Jung de Andrade (2021) The University of Texas at Dallas

\section{Li-Chyong Chen (2019)}

National Taiwan University

Dawnielle Farrar-Gaines (2019)

Johns Hopkins University

* Sharon C. Glotzer (2021)

University of Michigan

Claudia Gutiérrez-Wing (2019)

Instituto Nacional de

Investigaciones Nucleares

* Sarah Heilshorn (2021)

Stanford University

* Frances Houle (2021)

Lawrence Berkeley National

Laboratory

* Sergei V. Kalinin (2021)

Oak Ridge National Laboratory
* Kisuk Kang (2021)

Seoul National University

Lincoln J. Lauhon (2019)

Northwestern University

Paul C. McIntyre (2020)

Stanford University

Christopher A. Schuh (2020)

Massachusetts Institute of

Technology

Rachel A. Segalman (2020)

University of California,

Santa Barbara

Molly M. Stevens (2019)

Imperial College London

Ehrenfried Zschech (2020)

Fraunhofer Institute for Ceramic

Technologies and Systems

* Yusheng Zhao (2021)

Southern University of Science and Technology

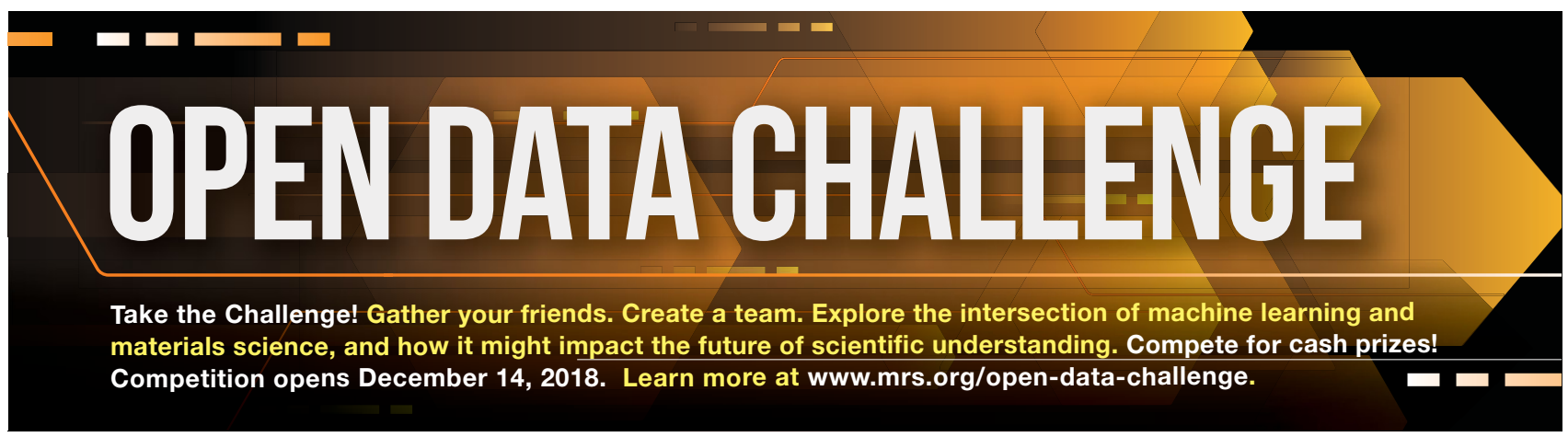

